\title{
A Review of the Monograph by D. L. Motov and M. M. Godneva "Fluoric, Sulfatic, and Fluorosulfatic Compounds of Group IV Elements: Formation \& Properties" 1
}

DOI: $10.1134 / \mathrm{S} 003602361103017 \mathrm{X}$

The monograph conserns the formation and principal characteristics of fluorides, sulfates and fluorosulfates of the Group IV elements. Presenting the results of numerous experimental studies published and translated in English earlier, it also provides analysis of the currently available literature.

The 21 physicochemical systems and eight sections examined by the authors are described from the viewpoint of formation of their compounds in aqueous media, with demarcating the formation regions, determining the chemical composition and key characteristics such as refractometric, roentgenometric, IR-spectroscopic, and thermal, and including data on heat treatment.

Systematic studies the systems have resulted in discovery of more than one hundred of new compounds and determining their structural parameters and types

\footnotetext{
${ }^{1}$ The article was translated by the authors.
}

of chemical bonds which, when compared with known data, has allowed a new class of compounds to be identified namely, fluorosulfatemetallates.

By comparing the systematized compounds, represented by 37 series and 9 groups and including 400 items, there has been predicted the possibility of the formation of about 30 new compounds of titanium, zirconium, and hafnium with various outer-sphere cations.

Apart from its chemical content, the book may serve as an atlas of infrared absorption spectra, derivatograms, roentgenometric, refractometric and crystallographic data on the compounds discussed.

The monograph be of interest for researchers involved in studies of transition elements chemistry, in running the manufacturing processes in fluorine chemistry as well as for college professors and students of relevant specialities.

N. N. Grishin, Dr. Sc. (Chemistry) 